\title{
Applying Cultural Elements to Ceramic Teaching-Using the Indigenous Pottery Kettles in Taiwan as an Example
}

\author{
Yuan-Lung Yu \\ National Yunlin University of Science and Technology, Yunlin County, Taiwan
}

\begin{abstract}
Culture is the pattern of human lifestyle. Over the course of history, culture originates from the operation of daily life and is often reflected on daily utensils. This study adopted literature review and content analysis to find out the factors affecting the formation of indigenous pottery kettles in Taiwan. Moreover, the cultural content of indigenous pottery kettles was analyzed, and the combination image technology was summarized, which can be used for the innovative content of ceramic teaching. The purposes of this study are: 1 . To analyze the constituting elements of indigenous pottery kettles in Taiwan; 2. To analyze the cultural elements of indigenous pottery kettles, and identify the factors affecting the combination images of pottery kettles; and 3. To apply cultural elements to combine images, in order to develop innovative ceramic teaching content. Over the past years, the author has deliberated over the cultural elements that influence the images on pottery kettles in local culture studies, and attempted to develop creation and teaching methods for combination images. The methodology discussed author's idea and it symbolized a format called "Metaphor Art."
\end{abstract}

Keywords: cultural elements, indigenous pottery kettles, teaching methods, metaphor art

\section{Introduction}

Against the backdrop of cultural globalization, the dominant foreign cultures have constantly influenced local cultures and gradually diminish the value of local cultures in diversity. Hence, many countries have paid attention to and strive to protect local cultures. Local cultures carry the cultural meaning of a nation, so they can highlight local features. Effective application of cultural factors can bring advantages to innovation. Moreover, a discussion on culture will lead to a new knowledge diffusion pattern in teaching.

The local culture in Taiwan combines the Chinese culture, the indigenous culture, and the colonization cultures in different periods. Under the oriental wave, Taiwan can promote the Taiwanese culture across the world, and develop the meaning of local cultures in the indigenous studies. This study takes the indigenous pottery kettle in Taiwan as the research subject, and analyzes the elements of the indigenous culture, in order to find out the workmanship applied in pottery kettle.

Through the analysis of the indigenous culture in Taiwan, this study expects to apply the achievements of the analysis to the modern ceramic teaching, so that students will be able to use cultural elements and reflect them in ceramic works. The teaching method, featuring the instruction, conversion, and application of culture can highlight local cultures in teaching and creation, as well as increase the possibility of innovation in ceramic courses.

Yuan-Lung Yu, associate professor, Department of Creative Design, National Yunlin University of Science and Technology. 


\section{The Research}

Before the 16th century, most of the inhabitants of this island were indigenous, specifically Austronesian, the most northern branch of the Austronesian. They lived and grew in Taiwan early in the Metal Age (400-2000 B.C.), so there are many cultural relics of the indigenous people in Taiwan that have constantly developed to date. If the workmanship and the pattern-making method of the indigenous people in Taiwan can be researched, it is possible to find out the corresponding workmanship procedure in the cultural discussion.

By the 17th century, some Han people had settled in Taiwan and lived with the indigenous people. Aside from frequent communication, there were intermarriage and trade between the two groups. However, the Taiwanese indigenous people lived in different tribes that scattered in different parts of Taiwan and had their own language and lifestyle. Currently, 16 indigenous groups have been officially recognized in Taiwan (see Figure 1).

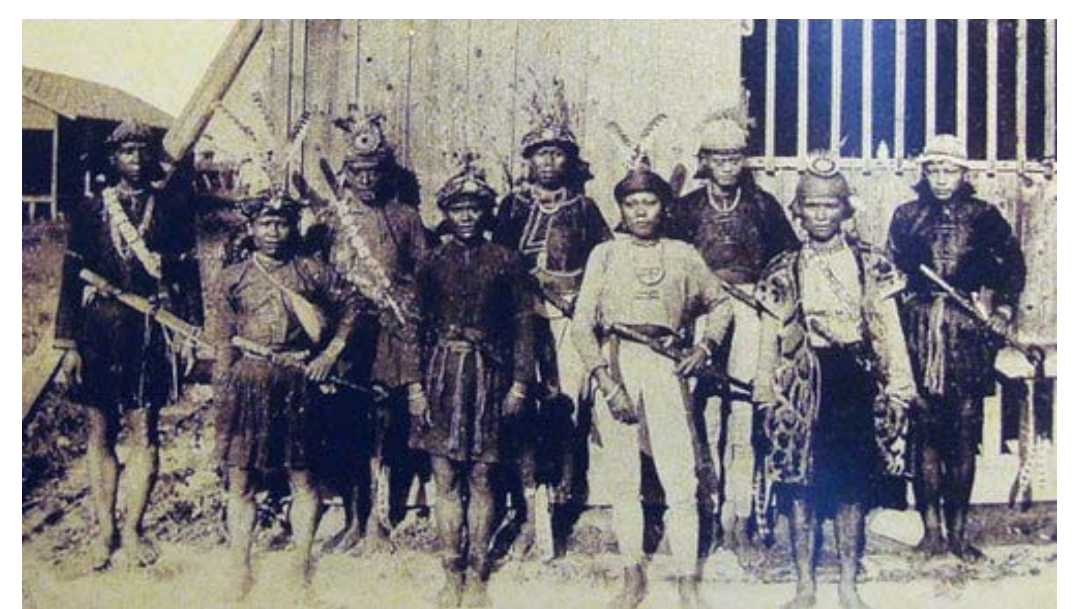

Figure 1. The geographical distribution of Paiwan clan and people. (Source: Tong, 1996)

One of the large number of the tribes in Taiwan, the Paiwan possess a fantastic and diversified tribal culture in the form of documents and relics, which is advocated by the scholars of anthropology and culture. Paiwan ("Payuan" in the Paiwan language, which was usually spelled as "Paiwan" before the writing system was established) refers to the Taiwanese indigenous people living on the two ends of the Hengchun Peninsula, and to the South of the Zhiben Mountain, in Southern Taiwan, with a population of 90,811. It consists of Raval and Vucul, two ethnic groups originating in the Beidawu Mountain.

In 2004, Suo-li Li, an expert in indigenous studies, wrote an article praising the Paiwan:

With abundant assets and skills, they have developed workmanship in weaving, wood sculpture, embroidery and beadwork on a large scale, which is worthy of promotion, in order to bring the cultural industry of the indigenous people in Taiwan to a new height.

\section{Research Purposes}

When we analyze the meaning of cultures and cultural relics, we should seek the meaning in their history or in the primitive system. Only by analyzing these cultural elements can we know the reasons for the existence of stories or myths. The elements of the stories can be converted into a possible source of creation, especially the cultural meaning and the functions of utensils in the stories. This imposes important requirements on the indigenous people who do not have a writing system. 
In the search of the cultural structure of the pottery kettle of the Paiwan, this paper has the following three research purposes:

1. To study the pottery kettle of the Taiwanese indigenous people to analyze its component elements;

2. To analyze the cultural elements in the pottery kettle of the Taiwanese indigenous people to find out the effects of the cultural elements on the combined images on pottery kettles;

3. To study cultural elements to combine images and innovate ceramic teaching.

The author tries to find out the history of the indigenous people through literature review and seek the archives and the information about the naming of the articles in the museum. The information shows the re-establishment and interpretation of the indigenous people as well as the cognitive images of them and the foundation that constitutes utensils. In this study on the indigenous culture, the author analyzes the cultural elements, and the achievements of this study can facilitate the innovation in the instruction of pattern graphics and texts and sculpture in the ceramic teaching.

\section{Research Method}

The literature review of this study focuses on the culture and ancient ceramics of the Paiwan, supported by relevant articles. It includes The Paiwan by Saa-lih Lee in 2004, Illustration of the Art History of Taiwan: Legends of Mountain and Ocean (Prehistory: Indigenous People) by Chong-ray Hsiao in 2003, and The Ancient Pottery Kettle of the Paiwan in Taiwan by Shien-min Jen in 1960. Most of the pictures and patterns of the ancient pottery kettles come from the National Museum of Prehistory and private owners.

According to the documents, the potteries with rope-like patterns were unearthed early in the prehistoric era (about 8,000 years ago). The indigenous people in Taiwan piled up the wood for burning and placed the pottery under the wood for a low-temperature burning, in order to produce the pottery kettles for daily use or sacrificial rites. For the Paiwan, pottery kettle symbolized their ancestor, as well as tribal status and wealth; pottery kettles were only possessed by the noble. The ceramic making of the Paiwan was lost, so these ceramics were handed down from the ancestors of the Paiwan. Etherealized, the ceramics were carved with the hundred-pace snake and the head pattern.

Of the indigenous people in Taiwan, the Paiwan has the most abundant ceramic culture. The pottery kettles of the leading ancestor were divided into four types_-yin-yang kettle, female kettle, human-form kettle, and male kettle. The yin-yang kettle was the most honorable and was placed on the both sides of a column in the house of the leading ancestor. Outsiders were prohibited from touching it, and it was also the most important bride price in marriage-based connections of the leading ancestor. Most of the pottery kettles of the Paiwan were yin-yang kettles, and the pottery kettles in the early times were round kettles without any pattern; later, the round kettles with a flat base and a sun pattern were created, followed by the rhombus kettles with a snake pattern. It was not until the modern times that the kettles with a circular base and diverse patterns were made.

Pottery kettle was called "Reretan" in the Paiwan language (see Figure 2). It represented the residence of ancestors in the earthly world, and its quantity indicated the wealth and status of the leaders. According to the myths of the Paiwan, the patterns on the pottery kettles, including "the sun and egg" and "pottery kettle give birth to a baby," were closely related to the leading ancestors.

The Paiwan regarded the hundred-pace snake as the ancestor of the noble and thus developed many taboos about it, which were a kind of worship, especially ancestral worship. There were several names for the 
hundred-pace snake in the Paiwan, such as "partner," "genuine," "ancestor," "elder," and "King of snake". Therefore, the image of the hundred-pace snake was used for decoration and, more importantly, to reinforce the hierarchical system (see Figure 3). The noble were seen as the descendants of the hundred-pace snake, so their clothes were decorated with the pattern of the hundred-pace snake, which was not found on the clothes of the civilians. Consequently, the patterns on the articles signify different statuses.

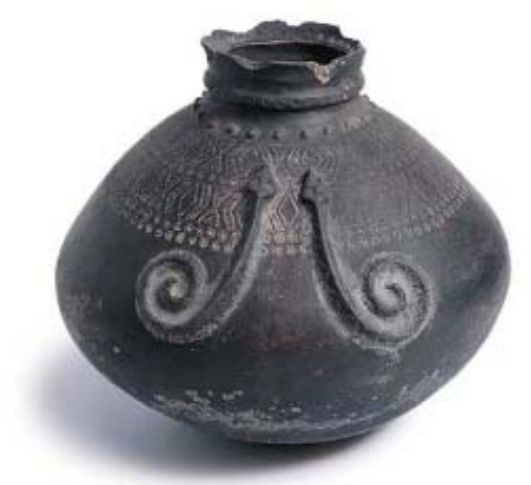

Figure 2. The yin-yang kettle of Paiwan. (Source: Retrieved April 10, 2016, from http://e-library.ceramics.ntpc.gov. /Journal/Content.aspx?Para=18\&TID=55)

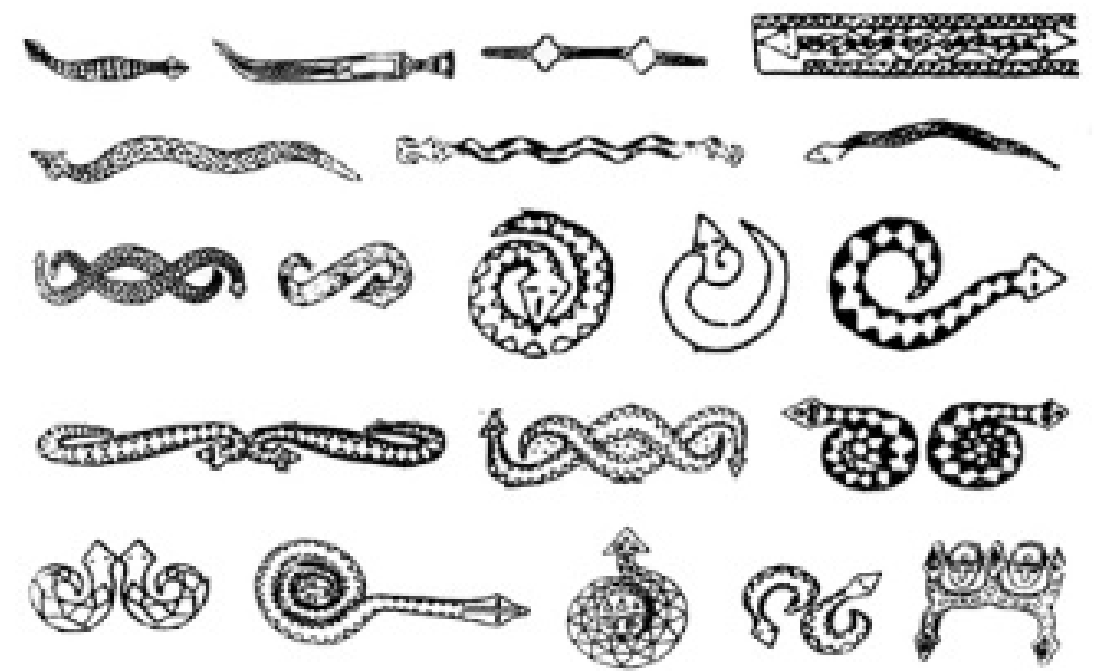

Figure 3. The hundred-pace snake's mark on pottery kettles. (Source: Exhibition of the Paiwan, Shihsanhang Museum of Archaeology)

The patterns of the hundred-pace snake on the articles were the triangular, rhombus, rectangular, and latticed variations, detached and simplified from the original pattern. In the early times, only the noble families were qualified to use symmetric patterns. Moreover, the pattern of the hundred-pace snake was often combined with the patterns of human head, human figure, deer, and kettle. The most frequently used pattern was the combination of the kettle and snake patterns.

The patterns on the male kettle were snake and human. On the upper side of the kettle was the image of the hundred-pace snake, which represented the male organ. On the female kettle was the pattern of the sun and small-protruded particles, which symbolized the female organs. The yin-yang kettle combines the features of the male and female kettles, featuring protruded nipple-shape objects and dents in the middle of the kettles. 
The above-mentioned shapes of the male and female kettles reflected the equality between men and women in the society. Moreover, the differences between sculptures and printed patterns were based on the features and nature of men. The shape combination was based on functionality and hierarchical system, revealing the life and culture of tribes. The sculptures on the pottery kettles highlighted the thinking of status and sexual symbol (see Table 1). It could be inferred that the ceramic workmanship of the Taiwan was gradually developed into multi-layered patterns according to the leaders and the elder of the tribes. It is the workmanship that integrates culture with the needs of life.

Table 1

The Mark and Significance on Pottery Kettles

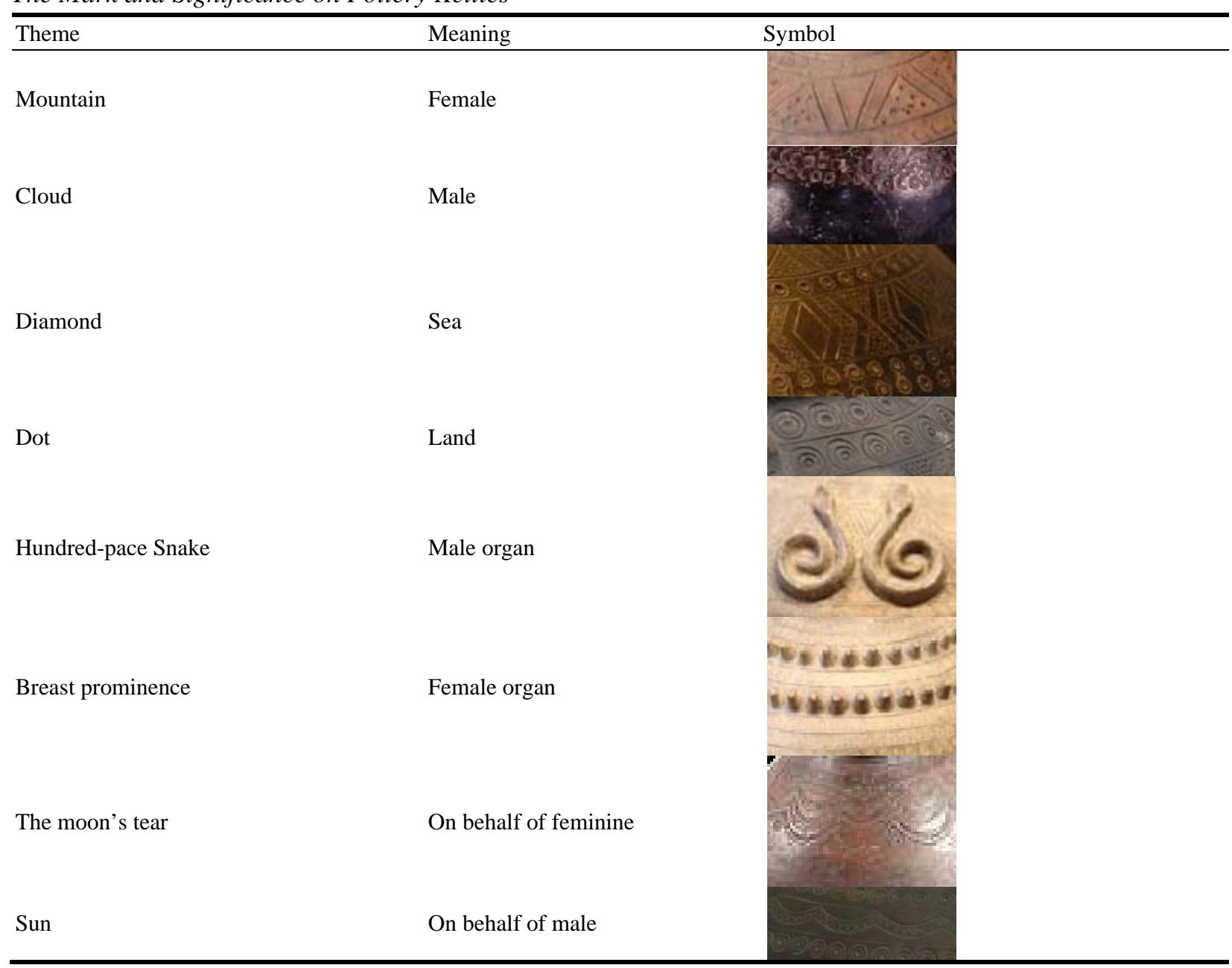

\section{Discussion}

\section{Principles of Image Combination in Paiwan Culture}

To find out the principles of image combination of the indigenous people, this study delves into the culture of the indigenous people in Taiwan. With the pottery kettle of the Paiwan as an example, it demonstrated the difference in the pattern and image of pottery kettles, which were caused by different statuses and values. The principles of the combination are described as follows:

1. To consider the functionality in myths and sacrificial rites; 
2. To show respect to the hierarchical system through the shape and pattern of pottery kettle;

3. To highlight the hierarchical system of the noble through the hundred-pace snake, the sun, and the birth of new lives in myths;

4. To indicate the status of the leaders of the Paiwan through the different sculpture of handicrafts, such as pottery kettle.

The historical preservation and oral description in the cultural aspect, as well as the application of the spiritual power carried forward in the ancient pottery kettles, endowed pottery kettles with functionality and gave it a more lofty status in sacrificial rites, weddings, and spiritual symbols. In particular, the difference in decoration between the male and female kettles highlighted the concept of the equality between men and women in the Paiwan. Such a hierarchical system embraced the equality to maintain a balanced, combined, and diversified development in the Paiwan. The interpretation of myths classified the ancient pottery kettles according to shape and led to the difference in pattern, cameo, and embossment. This is a typical case about the effects of cultural meaning on the ceramic making.

\section{Method of Teaching Pattern Structure}

According to the analysis, the pattern structure of the ancient pottery kettles of the Paiwan can be used to develop complete teaching methods and the principles of ceramic making. The ceramics of the Paiwan can be analyzed from a new perspective:

1. To collect the information about the natural shapes and myths of ceramics, and be familiar with the principle of their operation and application;

2. To understand the organic shapes and the simplified shapes consisting of animals, plants, minerals, and possible transformations of the myths;

3. To simplify shapes and convert the values of human according to cultural needs and principles;

4. To endow ceramics with the meaning and symbols related to human and show the hidden meaning of utensils through the conversion and evolution of cultural elements.

In the overall teaching and creation of ceramic art, the concept and application of the local culture can be used to equip utensils with the shape and structure of the local culture and the cultural meaning to be conveyed.

As for the skills of converting cultural elements, the form and meaning can be combined with systematic thinking to generate the ideas for ceramic creation (see Table 2). Moreover, systematic thinking of ceramic mark and shape can be developed to reduce metaphoric patterns and symbolism (Yeh, 1988).

The metaphoric method and personification were used in pottery making, in addition to the consideration of functionality and culture. The metaphoric image of nature made it possible to reveal the themes through historical relics and figures by combining images. In this way, pottery kettles can present the cultural elements hidden in the cameo in shape and pattern.

Symbolism, historical segments, and traditional marks can show words and signs in a simplified form. Therefore, the metaphoric image combination and the symbolic sign application can be used in the so-called "metaphor art" ceramic teaching, so as to create metaphor in creation with cultural elements. Cultural elements were separated from the original cultural system and then integrated into teaching. This is the reason why the indigenous people in Taiwan have such a time-honored and diversified form of workmanship culture. 
Table 2

The Methods for Combination Images

Title
Male
pottery kettles
$\begin{aligned} & \text { Female } \\ & \text { pottery kettles }\end{aligned}$

\section{Conclusion}

In modern times, the shape and pattern with such a combination of the cultural structure are not confined to genre or processing skills; hence, they spontaneously generate new forms. The hierarchical system and concept of combing diverse cultures of the Paiwan are the symbols of the diversity of the indigenous culture. Therefore, this study tries to interpret the traditional principles of pottery kettles of the Paiwan from a new perspective, so as to facilitate the update of ceramic creation and teaching, as well as the interpretation and construction in the concept of image combination.

\section{References}

Anderson, R. L. (1979). Art in small-scale societies. New Jersey: Prentice-Hall, Inc..

Chen, C. L. (1981). Study on the Indigenous culture in Taiwan. Taipei: Linking Publishing.

Chiang, S. Y. (1994). Thought on the preservation and interpretation of museums and Indigenous cultures (I). Museum Journal, $8(3)$.

Chu, T. (1987). Study on primitive cultures: A consideration of aesthetic problems. Beijing: Joint Publishing.

Chuang, P. H. (1980). The wood sculpture of the hundred-pace snake of the Paiwan. Artist, 59.

He, T. R. (1967). A comparative study on the Indigenous myths and legends in Taiwan. USA: Indiana University.

Hsiao, C. R. (2003). Illustration of the art history of Taiwan: 1. Legends of mountain and ocean (Prehistory: Indigenous people).

Taipei: Artist.

Tong, C. F. (1996). Gao sha chun qiu: Culture and art of Taiwan autochthon. Taipei: Rainbow Publication.

Hsu, Y. F. (2000). Artistic presentation under the hierarchical system of the Paiwan. Aboriginal Education Quarterly, $17,64-77$.

Jen, S. M. (1956). The carved kettle of the Paiwan. Bulletin of the Institute of Ethnology Academia Sinica, 2, 129-136.

Jen, S. M. (1960). The ancient pottery kettles of the Paiwan in Taiwan. Bulletin of the Institute of Ethnology Academia Sinica, 9 , $163-219$.

Kao, Y. R. (1998). The art of the indigenous people in Taiwan. Taipei: Dong Hwa.

Kong, Y. T. (1936). On the pottery kettle made by the Paiwan in Taiwan. The Ethnographical Journal of the South-East Asia and Formosa, 4(1). 
Li, S. L. (2004). Paiwan people. Taitung: National Taiwan Museum of Prehistory Publishing.

Liu, C. W. (1980). The indigenous culture and art in Taiwan. Taipei: Lion.

McCracken, G. (1987). Clothing as language: An object lesson in the study of the expressive properties of material culture. In B.

Reynolds \& M. A. Stott (Eds.), Material anthropology: Contemporary approaches to material culture (pp. 103-128). Lanham, M.D.: University Press of America.

Tu, E. W. (1958). The annual sacrificial rite of the Paiwan. Bulletin of the Department of Anthropology, 11, 100-103.

Van den Berghe, P. L., \& Charles, K. (1984). Introduction: Tourism and re-created ethnicity. Annals of Tourism Research, 11, 343-352.

Wang, S. S. (2001). Contemporary art of indigenous people in Taiwan. Taipei: National Taiwan Arts Education Center.

Wang, X. L. (1987). Chinese myths: The creation myths and faiths of ethnic groups. Taipei: China Times Publishing.

Yang, P. C. (1997). The hundred-pace snake totem art of the Paiwan and the Lukai people. Art Forum, pp. 49-64.

Yeh, G. S. (1988). Research clay modeling configuration systematization. National Hsinchu University of Education Journal, 2, 548-491.

Yin, C. C. (1994). Study on the compilation of the traditional myths and legends of the tribal groups in Taiwan. Taiwan: the Ministry of the Interior.

Yuen, K. (1987). Collection of myths. Taipei: Han Ching Culture. 